\title{
im DETAIL
}

Kosteneffizient

Bauen

Ökonomische Konzepte Wirtschaftliche Konstruktionen
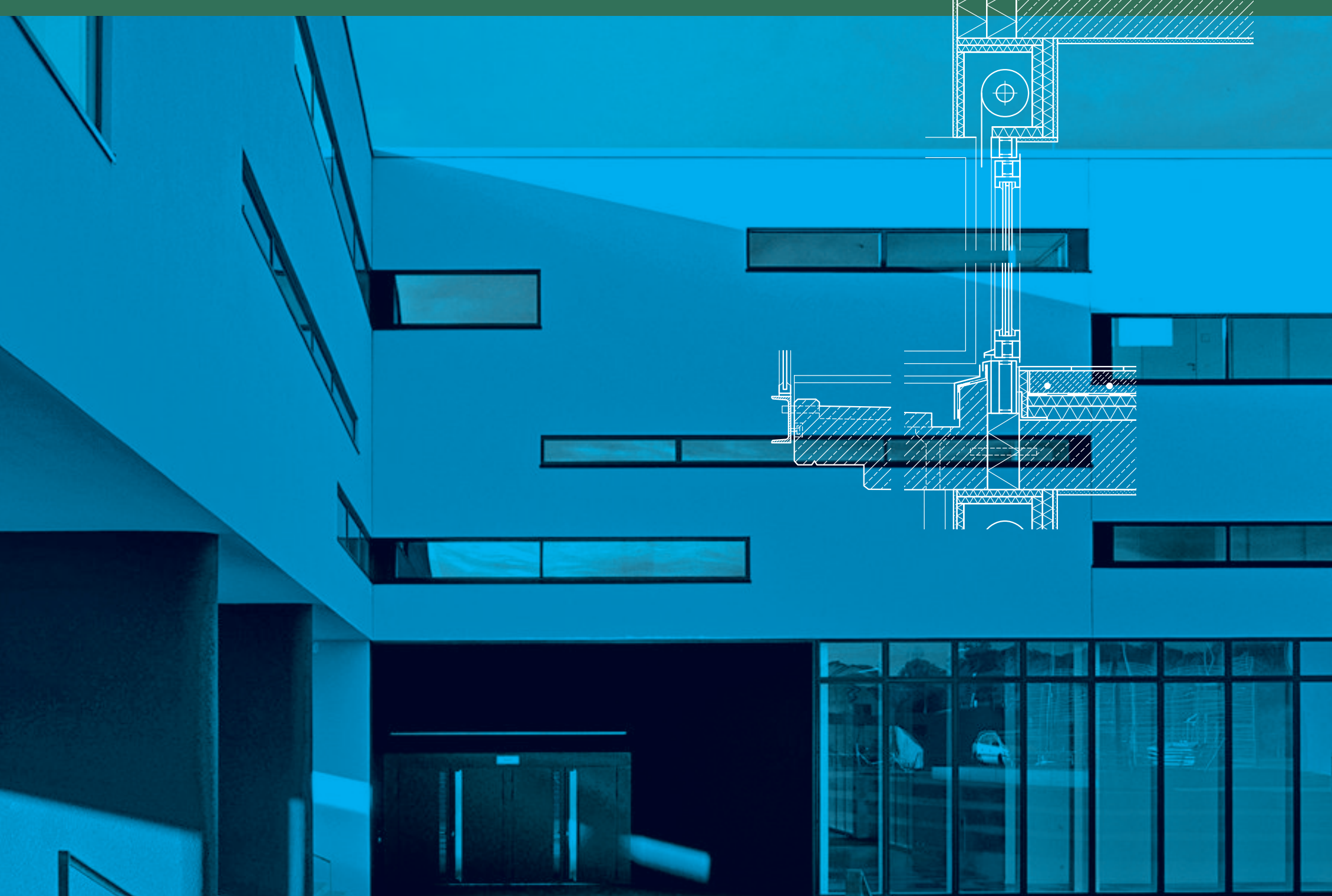

\section{Christian Schittich (Hrsg.)}

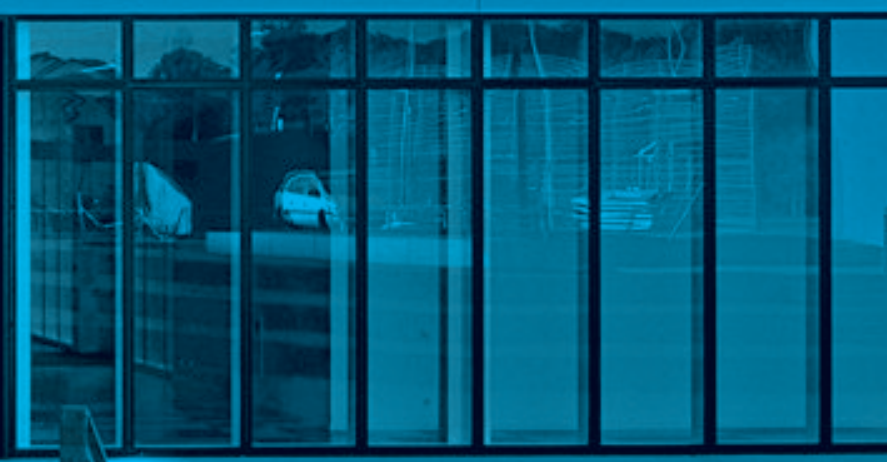

Edition Detail 

im DETAI L Kosteneffizient Bauen 



\section{im DETAI L \\ Kosteneffizient Bauen \\ Ökonomische Konzepte Wirtschaftliche Konstruktionen}

Christian Schittich (Hrsg.) 
Herausgeber: Christian Schittich

Redaktion: Astrid Donnert, Alexander Felix, Carola Laule,

Michaela Linder, Melanie Schmid, Cosima Strobl, Edith Walter

Zeichnungen: Nicola Kollmann, Marion Griese, Daniel Hajduk, Caroline Hörger

DTP: Peter Gensmantel, Andrea Linke, Roswitha Siegler, Simone Soesters

Ein Fachbuch aus der Redaktion DETAIL

Dieses Buch ist eine Kooperation zwischen Edition Detail - Institut für

internationale Architektur-Dokumentation GmbH \& Co. KG und

Birkhäuser Verlag AG

Bibliografische Information der Deutschen Nationalbibliothek Die Deutsche Nationalbibliothek verzeichnet diese Publikation in der Deutschen Nationalbibliografie; detaillierte bibliografische Daten sind im Internet über

<http://dnb.d-nb.de> abrufbar

Dieses Buch ist auch in englischer Sprache erhältlich (ISBN: 978-3-7643-8413-5).

• 2007 Institut für internationale Architektur-Dokumentation GmbH \& Co. KG Postfach 3306 60, D-80066 München und

Birkhäuser Verlag AG, Basel · Boston · Berlin, Postfach 133, CH-4010 Basel

Dieses Werk ist urheberrechtlich geschützt. Die dadurch begründeten Rechte, insbesondere die der Übersetzung, des Nachdrucks, des Vortrags, der Entnahme von Abbildungen und Tabellen, der Funksendung, der Mikroverfilmung oder der Vervielfältigung auf anderen Wegen und der Speicherung in Datenverarbeitungsanlagen, bleiben, auch bei nur auszugsweiser Verwertung, vorbehalten. Eine Vervielfältigung dieses Werkes oder von Teilen dieses Werkes ist auch im Einzelfall nur in den Grenzen der gesetzlichen Bestimmungen des Urheberrechtsgesetzes in der jeweils geltenden Fassung zulässig. Sie ist grundsätzlich vergütungspflichtig. Zuwiderhandlungen unterliegen den Strafbestimmungen des Urheberrechts.

Gedruckt auf säurefreiem Papier, hergestellt aus chlorfrei gebleichtem Zellstoff $(T C F \infty)$

Printed in Germany

Reproduktion:

Martin Härtl OHG, München

Druck und Bindung:

Kösel GmbH \& Co. KG, Altusried-Krugzell

ISBN: 978-3-7643-8413-5

987654321 